\title{
Association of body mass index with amnestic and non-amnestic mild cognitive impairment risk in elderly
}

Feng Wang, Minghui Zhao, Zhaoli Han, Dai Li, Shishuang Zhang, Yongqiang Zhang, Xiaodong Kong, Ning Sun, Qiang Zhang and Ping Lei*

\begin{abstract}
Background: Previous studies focused on the relationship between body mass index and cognitive disorder and obtained many conflicting results. This study explored the potential effects of body mass index on the risk of mild cognitive impairment (amnestic and non-amnestic) in the elderly.

Methods: The study enrolled 240 amnestic mild cognitive impairment patients, 240 non-amnestic mild cognitive impairment patients and 480 normal cognitive function controls. Data on admission and retrospective data at baseline (6 years ago) were collected from their medical records. Cognitive function was evaluated using MiniMental State Examination and Montreal Cognitive Assessment.

Results: Being underweight, overweight or obese at baseline was associated with an increased risk of amnestic mild cognitive impairment (OR: 2.30, 95\%Cl: $1.50 \sim 3.52$; OR: 1.74, 95\%Cl: $1.36 \sim 2.20$; OR: 1.71, 95\%Cl: $1.32 \sim 2.22$, respectively). Being overweight or obese at baseline was also associated with an increased risk of non-amnestic mild cognitive impairment (OR: 1.51,95\%Cl: $1.20 \sim 1.92$; OR: 1.52, 95\%Cl: $1.21 \sim 1.97$, respectively). In subjects with normal weights at baseline, an increased or decreased body mass index at follow-up was associated with an elevated risk of amnestic mild cognitive impairment (OR: 1.80, 95\% Cl: $1.10 \sim 3.05$; OR: 3.96, 95\%Cl: $2.88 \sim 5.49$, respectively), but only an increased body mass index was associated with an elevated risk of non-amnestic mild cognitive impairment (OR: 1.71, 95\%Cl: $1.16 \sim 2.59)$.
\end{abstract}

Conclusions: Unhealthy body mass index levels at baseline and follow-up might impact the risk of both types of mild cognitive impairment (amnestic and non-amnestic).

Keywords: Body mass index, Dementia, Mild cognitive impairment, Obesity, Weight

\section{Background}

Cognitive disorder is a common nervous system disease in the elderly, and it includes mild cognitive impairment (MCI), Alzheimer's disease (AD) and vascular dementia (VD) [1]. In recent decades, cognitive disorder has become one of the most important geriatric health problems. Around the world, dementia affected more than 45 million people in 2015 [2]. Many patients with dementia have a poor quality of life with some loss of dignity [3]. Individuals with MCI have a higher risk of dementia [4].

\footnotetext{
* Correspondence: leiping1974@163.com

Department of Geriatrics, Tianjin Medical University General Hospital; Tianjin Geriatrics Institute, No. 154, Anshan Road, Heping District, Tianjin 300052, China
}

(c) The Author(s). 2017 Open Access This article is distributed under the terms of the Creative Commons Attribution 4.0 International License (http://creativecommons.org/licenses/by/4.0/), which permits unrestricted use, distribution, and reproduction in any medium, provided you give appropriate credit to the original author(s) and the source, provide a link to the Creative Commons license, and indicate if changes were made. The Creative Commons Public Domain Dedication waiver (http://creativecommons.org/publicdomain/zero/1.0/) applies to the data made available in this article, unless otherwise stated.

Some interventions are therefore needed to terminate or slow the progression of MCI [5].

An increasing number of studies have focused on the relationship between body mass index (BMI) and cognitive disorder in elderly people. Ye et al. revealed that being underweight at baseline was associated with a higher risk of progression to $\mathrm{AD}$, whereas obesity at baseline predicted a lower risk [6]. Furthermore, a significant increase or decrease in BMI during the follow-up period reflected an increased risk of progression to $\mathrm{AD}$ [6]. Horie et al. reported that intentional weight loss through diet was associated with cognitive improvement in obese patients with MCI [7]. However, Alhurani et al. reported that increasing weight loss per decade from midlife to 
late life was a marker for MCI and might help identify persons who are at an increased risk for MCI [8]. This topic has not been well investigated, and there are many conflicting results.

MCI can be divided into amnestic MCI (aMCI) and non-amnestic MCI (naMCI). Memory loss is the major symptom of aMCI, which has a higher risk to convert to $\mathrm{AD}$ [9]. The non-amnestic form of MCI includes deficits other than memory and constitutes a higher risk to convert to other dementia forms such as diffuse Lewy body dementia [10]. Therefore, these two types of MCI may be implicated in diverse pathogenesis of dementia.

The associations of BMI with aMCI and naMCI may also be different, but this inference has not been proved. Therefore, we conducted a retrospective observational study enrolling nearly 1000 subjects to clarify the potential effects of baseline disorder and the follow-up changes of BMI on the risk of aMCI and naMCI in elderly people.

\section{Methods \\ Subjects}

Tianjin Medical University General Hospital Geriatrics Department provides medical services to the elderly in the district. Elderly individuals attend the Geriatric Outpatient Department of this hospital for health examination and disease counselling every 1 to 2 years. After permission, health data of the elderly have been collected for further research since 2008.

In the study, the inclusion criteria for MCI patients were predefined as follows: (1) Outpatients in Geriatrics Department, Tianjin Medical University General Hospital between January 1, 2014, and October 31, 2016, (2) over 60 years of age on admission, (3) meet the diagnostic criteria of aMCI or naMCI. (4) have medical records from the past 6 years, (5) have no history of MCI during the previous 6 years, and (6) agree to participate in the study. Overall, 240 patients with aMCI and 240 patients with naMCI were consecutively enrolled in the study according to the inclusion criteria.

A total of 480 controls with normal cognitive function were randomly selected from the Medical Examination Department, Tianjin Medical University General Hospital in the same period. All controls were over 60 years of age on admission.

Subjects who had Alzheimer's disease, vascular dementia, other types of dementia, myocardial infarction, cerebral infarction, hematencephalon, malignancies and mental diseases were excluded from the study.

All subjects or their legal guardians signed written informed consent forms. The study was approved by the Ethics Committee of Tianjin Medical University General Hospital.

\section{Data collection}

This was a retrospective observational study. Data on admission and at baseline were collected from medical records. "On admission" was defined as "January 1, 2014 and October 31, 2016", and "at baseline" was defined as "approximately 6 years ago, between January 1, 2008 and October 31, 2010". The follow-up period was 6 years for each MCI patient. The data collected from the medical records included demographic data, height, weight, education level, medical history, medication history, cognitive function and other useful information. In addition, genotyping was conducted in the subjects to determine their apolopoprotein E4 (APOE4) carrier status on admission.

\section{Diagnosis of mild cognitive impairment}

In the Geriatrics Department and Medical Examination Department, Mini-Mental State Examination (MMSE) and Montreal Cognitive Assessment (MoCA) were adopted for preliminary cognitive function determination. A subject with suspected cognitive disorders was recommended to a psychologist for further neurologic examination. The MCI patients were determined according to the diagnostic criteria (from Petersens et al.) by the psychologist [11]. The diagnosis was also approved by another psychologist.

The diagnostic criteria of MCI were as follows: (1) Evidence of memory or other cognitive disorders, (2) preservation of general cognitive and functional abilities, and (3) absence of diagnosed dementia. MCI patients with and without memory disorder were diagnosed separately with aMCI and naMCI.

Cognitive function was evaluated using MMSE and MoCA. In MMSE, subjects with fewer than 20 points and 24 points were considered to have cognitive disorder in subjects with primary school education and more than primary school education, respectively. In MoCA, subjects with fewer than 25 points and 26 points were considered to have cognitive disorder in subjects with equal to or less than 12 years of education and more than 12 years of education, respectively $[12,13]$.

A subject without suspected cognitive disorders or with normal scores in MMSE and MoCA was considered a subject with normal cognitive function.

\section{Body mass index and weight}

BMI was calculated using a formula: BMI $(\mathrm{kg} /$ $\mathrm{m}^{2}$ ) = weight $(\mathrm{kg}) /$ height $^{2}\left(\mathrm{~m}^{2}\right)$. Underweight (BMI $\left.<18.5 \mathrm{~kg} / \mathrm{m}^{2}\right)$, normal weight $\left(18.5 \sim 22.9 \mathrm{~kg} / \mathrm{m}^{2}\right)$, overweight $\left(23.0 \sim 24.9 \mathrm{~kg} / \mathrm{m}^{2}\right)$ and obesity (BMI $\left.\geq 25 \mathrm{~kg} / \mathrm{m}^{2}\right)$ were defined according to the World Health Organization's recommendations for Asian populations [14]. The subjects with an increased BMI (BMI increase of $>4 \%$ per year), decreased BMI (decrease of $>4 \%$ per year) or 
stable BMI (increase or decrease of $\leq 4 \%$ per year) were categorized according to the $4 \%$ cut-off for BMI [15].

\section{Statistical analysis}

Continuous and categorical variables were shown by mean \pm standard deviation (SD) and frequency. The difference of multiple continuous variables was determined using one-way variance analysis (ANOVA) with Duncan's post hoc test. The difference of categorical variables was determined using chi-square test. If a $P$ value was less than 0.05 , it was considered statistical significance. The association of MCI risk with BMI was evaluated using multivariate logistic regression analysis. The odds ratio $(O R)$ and $95 \%$ confidence interval $(C I)$ were calculated. If a $95 \% C I$ did not include the value "1", it was considered statistically significant. All analyses were conducted using SPSS version 19.0 (SPSS, iNC., Chicago, IL, USA).

\section{Results}

As shown in Table 1, there were more subjects with APOE4, type 2 diabetes mellitus (DM), hypertension, coronary heart disease (CHD) and metabolism syndrome (MS) in the aMCI and naMCI groups than in the control group at baseline $(P<0.05)$. More subjects had sulfonylureas, metformin and statins in the aMCI and naMCI groups compared with the control group $(P<0.05)$. Furthermore, the subjects in the naMCI group were more

Table 1 Baseline characteristics of patients with mild cognitive impairment and controls with normal cognitive function in the study

\begin{tabular}{|c|c|c|c|}
\hline Baseline & $\begin{array}{l}\mathrm{aMCl}^{\mathrm{a}} \\
(\mathrm{n}=240)\end{array}$ & $\begin{array}{l}\mathrm{naMCl}^{\mathrm{a}} \\
(n=240)\end{array}$ & $\begin{array}{l}\text { Control } \\
(n=480)\end{array}$ \\
\hline Male (n, \%) & $170(70.8)$ & $176(73.3)$ & $360(75.0)$ \\
\hline Age $(y r s, \text { mean } \pm S D)^{a}$ & $73.4 \pm 7.7$ & $72.6 \pm 9.6$ & $73.2 \pm 6.8$ \\
\hline Han nationality $(\mathrm{n}, \%)$ & $224(93.3)$ & $220(91.7)$ & $460(95.8)$ \\
\hline \multicolumn{4}{|l|}{ Education } \\
\hline$\leq 12$ years & $112(46.7)$ & $107(44.6)$ & $231(48.1)$ \\
\hline$>12$ years & $128(53.3)$ & $133(55.4)$ & $249(51.9)$ \\
\hline Type 2 DM $(n, \%)^{a}$ & $70(29.2) *$ & $66(27.5) *$ & $84(17.5)$ \\
\hline Hypertension (n, \%) & $170(70.8) * \#$ & $198(82.5) *$ & $256(53.3)$ \\
\hline $\mathrm{CHD}(\mathrm{n}, \%)^{\mathrm{a}}$ & $98(40.8) * \#$ & $134(55.8) *$ & $146(30.4)$ \\
\hline $\operatorname{MS}(n, \%)^{a}$ & $62(25.8) *$ & $60(25.0) *$ & $76(15.8)$ \\
\hline Sulfonylureas (n, \%) & $33(13.8) *$ & $35(14.6) *$ & $41(8.5)$ \\
\hline Metformin (n, \%) & $45(18.8) *$ & $43(17.9) *$ & $61(12.7)$ \\
\hline Insulin (n, \%) & $13(5.4)$ & $10(4.2)$ & $15(3.1)$ \\
\hline Statins (n, \%) & $53(22.1) *$ & $58(24.2) *$ & $70(14.6)$ \\
\hline APOE4 carriers $(n, \%)^{a}$ & $72(30.0) *$ & $61(25.4) *$ & $90(18.8)$ \\
\hline
\end{tabular}

${ }^{a} S D$ standard deviation, $D M$ diabetes mellitus, $C H D$ coronary heart disease, $M S$ metabolism syndrome, APOE4 apolopoprotein E4, aMCl amnestic mild cognitive impairment, naMCl non-amnestic mild cognitive impairment * Compared with control, $P<0.05$; ${ }^{\#}$ Compared with naMCl, $P<0.05$ likely to have hypertension and CHD than the subjects in the aMCI group at baseline $(P<0.05)$.

As shown in Table 2, there was no significant difference in the scores of MMSE and MoCA among the aMCI, naMCI and control groups at baseline $(P>0.05)$, which indicated that the subjects in the aMCI and naMCI groups had normal cognitive function at baseline. On admission, the scores of MMSE and MoCA were markedly decreased in the aMCI and naMCI groups than in the control group $(P<0.001)$, indicating that the subjects showed obvious cognitive disorders after 6 years.

As shown in Table 3, there was no difference in the baseline level of BMI among the aMCI, naMCI and control groups $(P>0.05)$, and there was no difference in the admission level (after 6 years) of BMI among these three groups $(P>0.05)$. The subjects were defined as underweight, normal weight, overweight or obese subjects according to their baseline BMI values. The aMCI and naMCI groups had more overweight and obese subjects $(P<0.05)$, and the control group had more normal weight subjects $(P<0.05)$. The underweight subjects were more common in the aMCI group than in the naMCI and control groups $(P<0.05)$. The subjects were also defined as increased BMI, stable BMI and decreased BMI subjects according to the change in BMI from baseline to admission (approximately 6 years). The increased BMI, stable $\mathrm{BMI}$ and decreased BMI subjects were equally distributed among the aMCI, naMCI and control groups $(P>0.05)$.

As shown in Table 4, being underweight, overweight or obese at baseline was associated with an increased risk of aMCI in the aMCI group (OR: $2.30,95 \% C I$ : $1.50 \sim$ 3.52; OR: 1.74, 95\%CI: $1.36 \sim 2.20 ;$ OR: 1.71 , $95 \% C I: 1.32 \sim 2.22$, respectively). In the naMCI group, being overweight or obese but not underweight at baseline was associated with an increased risk of naMCI $(O R: 1.51,95 \% C I: 1.20 \sim 1.92 ;$ OR: 1.52, 95\%CI: $1.21 \sim 1.97$; OR: $1.19,95 \% C I: 0.55 \sim 2.66$, respectively). After 6 years, subjects with an increased or decreased BMI did not exhibit any changes in MCI risk in the aMCI or naMCI groups.

As shown in Table 5, increased or decreased BMI in subjects with a normal weight at baseline were associated with an elevated risk of aMCI (OR: 1.80, 95\%CI: $1.10 \sim 3.05$; OR: 3.96, 95\%CI: $2.88 \sim 5.49$, respectively). However, only an increased BMI in the subjects with a normal weight at baseline was associated with an elevated risk of naMCI (OR: 1.71, 95\%CI: $1.16 \sim 2.59$ ). In addition, a decreased BMI in the subjects who were overweight or obese at baseline was related to a decreased risk of aMCI in the study (OR: 0.19, 95\% CI: $0.09 \sim 0.63$ ).

\section{Discussion}

In this study, several of the recognized risk factors for $\mathrm{MCI}$ were not equivalent among the aMCI, naMCI and 
Table 2 Scores of neuropsychologic examination in patients with mild cognitive impairment and the controls with normal cognitive function in the study

\begin{tabular}{|c|c|c|c|c|}
\hline & $\begin{array}{l}\mathrm{aMCl}^{\mathrm{a}} \\
(\mathrm{n}=240)\end{array}$ & $\begin{array}{l}\operatorname{naMCl}^{\mathrm{a}} \\
(\mathrm{n}=240)\end{array}$ & $\begin{array}{l}\text { Control } \\
(n=480)\end{array}$ & $P$ value \\
\hline \multicolumn{5}{|l|}{ MMSE $\left(\right.$ mean \pm SD) ${ }^{a}$} \\
\hline Total at baseline & $28.0 \pm 1.1$ & $28.1 \pm 1.1$ & $28.0 \pm 1.1$ & 0.313 \\
\hline Underweight at baseline & $27.7 \pm 1.3$ & $27.2 \pm 0.7$ & $27.9 \pm 1.0$ & 0.640 \\
\hline Normal weight at baseline & $28.0 \pm 1.2$ & $28.1 \pm 1.2$ & $28.0 \pm 1.1$ & 0.765 \\
\hline Overweight at baseline & $27.9 \pm 1.0$ & $28.4 \pm 1.1$ & $28.2 \pm 1.2$ & 0.080 \\
\hline Obese at baseline & $27.9 \pm 1.1$ & $27.9 \pm 1.1$ & $28.0 \pm 1.1$ & 0.881 \\
\hline Total on admission & $24.1 \pm 1.2 *$ & $24.1 \pm 1.1 *$ & $28.1 \pm 1.2$ & $<0.001$ \\
\hline$P$ value ${ }^{b}$ & $<0.001$ & $<0.001$ & 0.672 & \\
\hline \multicolumn{5}{|l|}{$\operatorname{MoCA}(\text { mean } \pm S D)^{a}$} \\
\hline Total at baseline & $28.4 \pm 1.1$ & $28.5 \pm 1.1$ & $28.4 \pm 1.1$ & 0.529 \\
\hline Underweight at baseline & $28.6 \pm 1.3$ & $28.7 \pm 1.4$ & $28.4 \pm 1.0$ & 0.872 \\
\hline Normal weight at baseline & $28.4 \pm 1.1$ & $28.5 \pm 1.1$ & $28.4 \pm 1.1$ & 0.684 \\
\hline Overweight at baseline & $28.3 \pm 1.1$ & $28.4 \pm 1.2$ & $28.4 \pm 1.2$ & 0.835 \\
\hline Obese at baseline & $28.4 \pm 1.1$ & $28.6 \pm 1.1$ & $28.4 \pm 1.1$ & 0.481 \\
\hline Total on admission & $24.4 \pm 1.1 *$ & $24.4 \pm 1.1^{*}$ & $28.4 \pm 1.1$ & $<0.001$ \\
\hline$P$ value ${ }^{b}$ & $<0.001$ & $<0.001$ & 0.690 & \\
\hline
\end{tabular}

${ }^{a} M M S E$ Mini-Mental State Examination, MoCA Montreal Cognitive Assessment, SD standard deviation, aMCl amnestic mild cognitive impairment, naMCl nonamnestic mild cognitive impairment

${ }^{\mathrm{b}}$ Difference of the scores between total at baseline and total on admission was determined by independent sample $\mathrm{t}$ test. If a $P$ value $<0.05$, it was considered significant

' Difference of the scores among aMCl, naMCI and control groups was determined by one-way variance analysis (ANOVA) with Duncan's post hoc test. If a $P$ value $<0.05$, it was considered significant. ${ }^{*}$ Compared with control, $P<0.05$

control groups. For example, onset of type 2 DM, hypertension and CHD at baseline were more common in the aMCI and naMCI groups compared with the control group. These findings were consistent with previous studies [16-18]. Two vascular-related diseases (hypertension and CHD) were more dominant in the naMCI group than in the aMCI group. This result partly proved that naMCI might be more closely related to vascular disorders, and was also consistent with some previous studies [19-21]. In addition, some hypoglycemic and hypolipidemic therapies, such as sulfonylureas, metformin, insulin and statins, affected the body weight and BMI [22]. In the study, these factors were also not distributed equally among the three groups.

Table 3 Body mass index of patients with mild cognitive impairment and the controls with normal cognitive function in the study

\begin{tabular}{|c|c|c|c|}
\hline & $\begin{array}{l}\mathrm{aMCl}^{\mathrm{a}} \\
(\mathrm{n}=240)\end{array}$ & $\begin{array}{l}\text { naMCl }^{\text {a }} \\
(n=240)\end{array}$ & $\begin{array}{l}\text { Control } \\
(n=480)\end{array}$ \\
\hline BMI at baseline $\left(\mathrm{kg} / \mathrm{m}^{2}, \text { mean } \pm \mathrm{SD}\right)^{\mathrm{a}, \mathrm{b}}$ & $23.5 \pm 4.0$ & $23.3 \pm 3.1$ & $\overline{23.5 \pm 4.1}$ \\
\hline BMI on admission $\left(\mathrm{kg} / \mathrm{m}^{2}\right.$, mean $\left.\pm \mathrm{SD}\right)$ & $23.6 \pm 3.3$ & $23.4 \pm 3.0$ & $23.5 \pm 2.9$ \\
\hline \multicolumn{4}{|l|}{ BMI at baseline } \\
\hline Underweight (n, \%) & $11(4.6) * \#$ & $4(1.7)$ & $9(1.9)$ \\
\hline Normal weight (n, \%) & $87(36.3) *$ & $100(41.7) *$ & $267(55.6)$ \\
\hline Overweight (n, \%) & $77(32.1) *$ & $73(30.4) *$ & $110(22.9)$ \\
\hline Obese $(n, \%)$ & $65(27.1) *$ & $63(26.3) *$ & $94(19.6)$ \\
\hline \multicolumn{4}{|l|}{ BMl change } \\
\hline Increased (n, \%) & $33(13.8)$ & $28(11.7)$ & $52(10.4)$ \\
\hline Stable $(n, \%)$ & $181(75.4)$ & $188(78.3)$ & $392(81.7)$ \\
\hline Decreased (n, \%) & 26 (10.8) & $24(10.0)$ & $38(7.9)$ \\
\hline
\end{tabular}

${ }^{\mathrm{a}} B M \mathrm{I}$ body mass index, $S D$ standard deviation, $a \mathrm{MCl}$ amnestic mild cognitive impairment, naMCI non-amnestic mild cognitive impairment

b Difference of three continuous variables was determined by one-way variance analysis (ANOVA) with Duncan's post hoc test. Difference of categorical variables was determined using chi-square test. If a $P$ value $<0.05$, it was considered significant. * Compared with control, $P<0.05 ; \# C o m p a r e d$ with naMCl, $P<0.05$ 
Table 4 Association of body mass index with amnestic and non-amnestic mild cognitive impairment risk

\begin{tabular}{|c|c|c|c|c|c|c|}
\hline & $\begin{array}{l}\mathrm{aMCl} \\
(\mathrm{n})\end{array}$ & $\begin{array}{l}\text { Control } \\
\text { (n) }\end{array}$ & $\begin{array}{l}\text { aMCI vs Control } \\
\text { OR }(95 \% \mathrm{Cl})^{a, b}\end{array}$ & $\begin{array}{l}\text { naMCl } \\
(n)\end{array}$ & $\begin{array}{l}\text { Control } \\
\text { (n) }\end{array}$ & $\begin{array}{l}\text { naMCI vs Control } \\
\text { OR }(95 \% \mathrm{Cl})^{\text {a, b }}\end{array}$ \\
\hline \multicolumn{7}{|l|}{ BMI at baseline ${ }^{a}$} \\
\hline Normal weight & 87 & 267 & Reference & 100 & 267 & Reference \\
\hline Underweight & 11 & 9 & $2.30(1.50 \sim 3.52)$ & 4 & 9 & $1.19(0.55 \sim 2.66)$ \\
\hline Overweight & 77 & 110 & $1.74(1.36 \sim 2.20)$ & 73 & 110 & $1.51(1.20 \sim 1.92)$ \\
\hline Obese & 65 & 94 & $1.71(1.32 \sim 2.22)$ & 63 & 94 & $1.52(1.21 \sim 1.97)$ \\
\hline \multicolumn{7}{|l|}{ BMI change } \\
\hline Stable & 181 & 392 & Reference & 188 & 392 & Reference \\
\hline Increased & 33 & 52 & $1.27(0.97 \sim 1.70)$ & 28 & 52 & $1.11(0.81 \sim 1.55)$ \\
\hline Decreased & 26 & 38 & $1.35(0.99 \sim 1.85)$ & 24 & 38 & $1.23(0.89 \sim 1.72)$ \\
\hline
\end{tabular}

${ }^{\mathrm{a}} \mathrm{BMI}$ body mass index, $\mathrm{aMCl}$ amnestic mild cognitive impairment, naMCl non-amnestic mild cognitive impairment, $\mathrm{OR}$ odds ratio, $\mathrm{Cl}$ confidence interval

${ }^{b}$ Multivariable logistic regression analysis was adjusted by gender, age, race, education level, medication history, apolopoprotein E4 carrier, onset of type 2

diabetes mellitus, hypertension, coronary heart disease and metabolism syndrome

Considering the confounding factors mentioned above, multivariate logistic regression analysis was adopted in the study. It revealed that being overweight or obese at baseline was associated with an approximately $50-70 \%$ increased risk of all types of MCI (aMCI and naMCI). The possible explanation is that obesity triggered both vascular and non-vascular disorders (e.g. atherosclerosis and inflammation) and promoted the risk of cognitive impairment [23, 24]. However, being underweight at baseline was related only to an increased risk of aMCI but not of naMCI. There were two possible explanations. First, the sample size was too small, and the power of the test was limited. Second, being underweight might keep people away from many vascular risk factors and reduce the risk of naMCI [25]. However, more research should be conducted in the future.
This study also suggested that the relationship between the BMI change observed in the study period (approximately 6 years) and the risk of MCI was partly affected by the baseline BMI. In subjects with a normal weight at baseline, an increased BMI in the study period was related to the onset of two types of MCI (aMCI and naMCI), but a decreased BMI in the same period was implicated only in the onset of aMCI. These findings were similar to the relationship observed between the baseline BMI and the risk of MCI.

In subjects who were overweight or obese at baseline, a further increase in BMI in the study period was not associated with an elevated risk of MCI, and a dose-effect relationship between BMI and MCI was not proved. In the same group of subjects, a decreased BMI in the study period showed a protective effect on aMCI risk, but this was not observed in subjects with naMCI.

Table 5 Association of body mass index change with amnestic and non-amnestic mild cognitive impairment risk according to baseline body mass index level

\begin{tabular}{|c|c|c|c|c|c|c|}
\hline & $\begin{array}{l}\mathrm{aMCl} \\
\text { (n) }\end{array}$ & $\begin{array}{l}\text { Control } \\
\text { (n) }\end{array}$ & $\begin{array}{l}\text { aMCI vs Control } \\
\text { OR }(95 \% C l)^{a, b}\end{array}$ & $\begin{array}{l}\text { naMCl } \\
\text { (n) }\end{array}$ & $\begin{array}{l}\text { Control } \\
\text { (n) }\end{array}$ & $\begin{array}{l}\text { naMCI vs Control } \\
\text { OR }(95 \% \mathrm{Cl})^{\mathrm{a}, \mathrm{b}}\end{array}$ \\
\hline \multicolumn{7}{|c|}{ Underweight at baseline } \\
\hline Stable BMI ${ }^{\mathrm{a}}$ & 10 & 4 & Reference & 3 & 4 & Reference \\
\hline Increased BMI & 1 & 5 & $0.27(0.09 \sim 1.51)$ & 1 & 5 & $0.43(0.09 \sim 2.86)$ \\
\hline \multicolumn{7}{|c|}{ Normal weight at baseline } \\
\hline Stable BMI & 51 & 231 & Reference & 73 & 222 & Reference \\
\hline Increased BMI & 12 & 26 & $1.80(1.10 \sim 3.05)$ & 17 & 24 & $1.71(1.16 \sim 2.59)$ \\
\hline Decreased BMI & 24 & 10 & $3.96(2.88 \sim 5.49)$ & 10 & 21 & $1.35(0.79 \sim 2.27)$ \\
\hline \multicolumn{7}{|c|}{ Overweight or obese at baseline } \\
\hline Stable BMI & 120 & 155 & Reference & 112 & 162 & Reference \\
\hline Increased BMI & 20 & 21 & $1.17(0.85 \sim 1.62)$ & 10 & 25 & $0.81(0.52 \sim 1.41)$ \\
\hline Decreased BMI & 2 & 28 & $0.19(0.09 \sim 0.63)$ & 14 & 17 & $1.17(0.80 \sim 1.78)$ \\
\hline
\end{tabular}

${ }^{\mathrm{a}} \mathrm{BMI}$ body mass index, $a \mathrm{MCl}$ amnestic mild cognitive impairment, $\mathrm{naMCl}$ non-amnestic mild cognitive impairment, $\mathrm{OR}$ odds ratio, $\mathrm{Cl}$ confidence interval

${ }^{\mathrm{b}}$ Multivariable logistic regression analysis was adjusted by gender, age, race, education level, medication history, apolopoprotein E4 carrier, onset of type 2

diabetes mellitus, hypertension, coronary heart disease and metabolism syndrome 
Furthermore, in subjects who were underweight at baseline, the study did not report an effect of increased BMI on MCI risk. The potential explanation was that the lack of data reduced the power of the test. More studies should thus be conducted.

There are several potential mechanisms that might explain the relationship between BMI and MCI risk. First, previous studies reported that overweight and obesity caused a variety of brain pathological changes, such as cerebral circulation insufficiency, neuronal injury and dysfunction, brain atrophy, inflammatory disorder, elevated $\beta$-amyloid precursor protein and tau protein expression [26-29], which might increase the MCI risk. Second, weight-loss-related energy dysmetabolism and hormone regulation disorder might affect the risk of the disease. Third, considering potential reverse causality, some prodromal symptoms of cognitive disorder (such as depression and apathy) could reduce appetite and cause weight loss [30]. Several dementia-related protein deposits have been documented in the olfactory pathway, and dysosmia may lead to appetite loss and maransis [31].

Previous studies have revealed that APOE4 might be an independent risk factor for AD and that APOE polymorphism might be involved in VD [32, 33]. Healthy people with APOE4 had a greater dementia risk, and dementia patients with APOE4 showed a worse response to therapy $[34,35]$. In the study, APOE4 carriers were more common in the MCI groups than in the control group. Multivariate regression analysis, however, removed the effect of APOE polymorphism, and exciting results were reported.

\section{Conclusion}

This study revealed that being overweight or obese may be an independent risk factor for aMCI and naMCI, as was weight gain in people who originally had a normal weight. Being underweight was another independent risk factor for aMCI but not for naMCI. Furthermore, weight loss in overweight/obese people and normal weight people might separately exert protective and pathogenic effects on aMCI. Taken together, overweight/obesity and weight gain might affect the risk of two types of MCI (aMCI and naMCI), and underweight and weight loss may only be implicated in the risk of aMCI. However, this is a preliminary study, so further research is necessary in large community based sample to validate our conclusion and reveal the mechanisms involved.

\section{Abbreviations}

AD: Alzheimer's disease; aMCl: Amnestic MCl; APOE4: Apolopoprotein E4; BMI: Body mass index; CHD: Coronary heart disease; Cl: Confidence interval; DM: Diabetes mellitus; MCI: Mild cognitive impairment; MMSE: Mini-Mental State Examination; MoCA: Montreal Cognitive Assessment; MS: Metabolism syndrome; naMCl: Non-amnestic MCl; OR: Odds ratio; SD: Standard deviation; VD: Vascular dementia

\section{Acknowledgements}

Not applicable.

\section{Funding}

This project is supported by National Clinical Key Subject Construction Project of NHFPC Fund. This project is also supported by National Natural Science Fund $(81,471,252$ and $81,670,086)$. The funding body had no involvement in any stage of the study.

\section{Availability of data and materials}

Not applicable. The subjects in the study did not agree to open these data. We had signed an agreement with the subjects. In the agreement, we promised not to disclose the subjects' data.

\section{Authors' contributions}

WF and LP contributed to the study concept and design. WF, LP, ZM, HZ, LD and $S N$ were involved in the acquisition of data. WF, LP, ZS, ZY, KX and ZQ conducted the analysis and interpretation of data. WF, LP, SN and ZQ worked on the preparation of manuscript. All authors read and approved the final manuscript.

\section{Ethics approval and consent to participate}

A written informed consent was obtained from subjects who had normal cognitive function. For those with cognitive impairment, we got the written informed consent from their legal guardians. The present study had been approved by the Ethics Committee of Tianjin Medical University General Hospital.

Consent for publication

Not applicable.

\section{Competing interests}

The authors declare that they had no competing interests.

\section{Publisher's Note}

Springer Nature remains neutral with regard to jurisdictional claims in published maps and institutional affiliations.

Received: 19 April 2017 Accepted: 6 September 2017

Published online: 15 September 2017

References

1. Beck CK, Heacock P, Rapp CG, Shue V. Cognitive impairment in the elderly. Nurs Clin North Am. 1993;28(2):335-47.

2. GBD 2015 Disease and Injury Incidence and Prevalence Collaborators. Global, regional, and national incidence, prevalence, and years lived with disability for 310 diseases and injuries, 1990-2015: a systematic analysis for the Global Burden of Disease Study 2015. Lancet. 2016;388(10053):1545-602.

3. Olsen C, Pedersen I, Bergland A, Enders-Slegers MJ, Jøranson N, Calogiuri G, et al. Differences in quality of life in home-dwelling persons and nursing home residents with dementia - a cross-sectional study. BMC Geriatr. 2016;16:137.

4. Luchsinger JA, Reitz C, Patel B, Tang MX, Manly JJ, Mayeux R. Relation of diabetes to mild cognitive impairment. Arch Neurol. 2007;64(4):570-5.

5. Dannhauser TM, Cleverley M, Whitfield TJ, Fletcher BC, Stevens T, Walker Z. A complex multimodal activity intervention to reduce the risk of dementia in mild cognitive impairment-ThinkingFit: pilot and feasibility study for a randomized controlled trial. BMC Psychiatry. 2014:14:129.

6. Ye BS, Jang EY, Kim SY, Kim EJ, Park SA, Lee Y, et al. Unstable body mass index and progression to probable Alzheimer's disease dementia in patients with amnestic mild cognitive impairment. J Alzheimers Dis. 2016;49(2):483-91.

7. Horie NC, Serrao VT, Simon SS, Gascon MR, Dos Santos AX, Zambone MA, et al. Cognitive effects of intentional weight loss in elderly obese individuals with mild cognitive impairment. J Clin Endocrinol Metab. 2016;101(3):1104-12.

8. Alhurani RE, Vassilaki M, Aakre JA, Mielke MM, Kremers WK, Machulda MM, et al. Decline in weight and incident mild cognitive impairment: Mayo clinic study of aging. JAMA Neurol. 2016;73(4):439-46.

9. Grundman M, Petersen RC, Ferris SH, Thomas RG, Aisen PS, Bennett DA, et al. Mild cognitive impairment can be distinguished from Alzheimer disease and normal aging for clinical trials. Arch Neurol. 2004;61(1):59-66. 
10. Csukly G, Sirály E, Fodor Z, Horváth A, Salacz P, Hidasi Z, et al. The differentiation of amnestic type $\mathrm{MCl}$ from the non-amnestic types by structural MRI. Front Aging Neurosci. 2016;8:52.

11. Petersen RC. Mild cognitive impairment as a diagnostic entity. J Intern Med. 2004;256(3):183-94.

12. Molloy DW, Standish TI. A guide to the standardized mini-mental state examination. Int Psychogeriatr. 1997;9(Suppl 1):87-94. discussion 143-50

13. Olson RA, Chhanabhai T, McKenzie M. Feasibility study of the Montreal Cognitive Assessment (MoCA) in patients with brain metastases. Support Care Cancer. 2008;16(11):1273-8.

14. Expert Consultation WHO. Appropriate body-mass index for Asian populations and its implications for policy and intervention strategies. Lancet. 2004;363(9403):157-63.

15. Soto ME, Secher M, Gillette-Guyonnet S, Abellan van Kan G, Andrieu S, Nourhashemi F, et al. Weight loss and rapid cognitive decline in community-dwelling patients with Alzheimer's disease. J Alzheimers Dis. 2012;28(3):647-54.

16. Winkler A, Dlugaj M, Weimar C, Jöckel KH, Erbel R, Dragano N, et al. Association of diabetes mellitus and mild cognitive impairment in middleaged men and women. J Alzheimers Dis. 2014;42(4):1269-77.

17. Roberts RO, Knopman DS, Geda YE, Cha RH, Roger VL, Petersen RC. Coronary heart disease is associated with non-amnestic mild cognitive impairment. Neurobiol Aging. 2010;31(11):1894-902.

18. Bai J, Wei P, Zhao N, Xiao Y, Yang C, Zhong J, et al. A study of mild cognitive impairment in veterans: role of hypertension and other confounding factors. Neuropsychol Dev Cogn B Aging Neuropsychol Cogn. 2016;23(6):703-15.

19. Li W, Wang T, Xiao S. Type 2 diabetes mellitus might be a risk factor for mild cognitive impairment progressing to Alzheimer's disease. Neuropsychiatr Dis Treat. 2016;12:2489-95.

20. Hubenak J, Tuma I, Bazant J. Association of arterial hypertension and cognitive impairment in euthymic bipolar disorder. Neuro Endocrinol Lett. 2015;36(3):294-300.

21. Roberts RO, Geda YE, Knopman DS, Cha RH, Pankratz VS, Boeve BF, et al. Cardiac disease associated with increased risk of nonamnestic cognitive impairment: stronger effect on women. JAMA Neurol. 2013;70(3):374-82.

22. Domecq JP, Prutsky G, Leppin A, Sonbol MB, Altayar O, Undavalli C, et al. Clinical review: drugs commonly associated with weight change: a systematic review and meta-analysis. J Clin Endocrinol Metab. 2015;100(2):363-70.

23. Knopman DS, Gottesman RF, Sharrett AR, Wruck LM, Windham BG, Coker L, et al. Mild cognitive impairment and dementia prevalence: the atherosclerosis risk in communities neurocognitive study (ARIC-NCS). Alzheimers Dement (Amst). 2016;2:1-11.

24. Tay L, Lim WS, Chan M, Ye RJ, Chong MS. The independent role of inflammation in physical frailty among older adults with mild cognitive impairment and mild-to-moderate Alzheimer's disease. J Nutr Health Aging. 2016;20(3):288-99.

25. Wu L, He Y, Jiang B, Liu M, Wang J, Yang S, et al. The association between the prevalence, treatment and control of hypertension and the risk of mild cognitive impairment in an elderly urban population in China. Hypertens Res. 2016;39(5):367-75.

26. Gorelick PB, Scuteri A, Black SE, Decarli C, Greenberg SM, ladecola C, et al. Vascular contributions to cognitive impairment and dementia: a statement for healthcare professionals from the american heart association/american stroke association. Stroke. 2011:42(9):2672-713.

27. Lee YH, Martin JM, Maple RL, Tharp WG, Pratley RE. Plasma amyloid-beta peptide levels correlate with adipocyte amyloid precursor protein gene expression in obese individuals. Neuroendocrinology. 2009;90(4):383-90.

28. Koga S, Kojima A, Kuwabara S, Yoshiyama Y. Immunohistochemical analysis of tau phosphorylation and astroglial activation with enhanced leptin receptor expression in diet-induced obesity mouse hippocampus. Neurosci Lett. 2014;571:11-6.

29. Sumarac-Dumanovic M, Stevanovic D, Ljubic A, Jorga J, Simic M, Stamenkovic-Pejkovic D, et al. Increased activity of interleukin-23/interleukin17 proinflammatory axis in obese women. Int J Obes. 2009;33(1):151-6.

30. Geda YE, Roberts RO, Mielke MM, Knopman DS, Christianson TJ, Pankratz VS, et al. Baseline neuropsychiatric symptoms and the risk of incident mild cognitive impairment: a population-based study. Am J Psychiatry. 2014; 171(5):572-81.

31. Doty RL. Olfaction in Parkinson's disease and related disorders. Neurobiol Dis. 2012;46(3):527-52.
32. Seripa D, Matera MG, D'Andrea RP, Gravina C, Masullo C, Daniele A, et al Alzheimer disease risk associated with APOE4 is modified by STH gene polymorphism. Neurology. 2004;62(9):1631-3.

33. Allan $\mathrm{CL}$, Ebmeier KP. The influence of ApoE4 on clinical progression of dementia: a meta-analysis. Int J Geriatr Psychiatry. 2011;26(5):520-6.

34. Villeneuve S, Brisson D, Marchant NL, Gaudet D. The potential applications of Apolipoprotein E in personalized medicine. Front Aging Neurosci. 2014;6: 154.

35. Risner ME, Saunders AM, Altman JF, Ormandy GC, Craft S, Foley IM, et al. Efficacy of rosiglitazone in a genetically defined population with mild-tomoderate Alzheimer's disease. Pharmacogenomics J. 2006;6(4):246-54.

\section{Submit your next manuscript to BioMed Central and we will help you at every step:}

- We accept pre-submission inquiries

- Our selector tool helps you to find the most relevant journal

- We provide round the clock customer support

- Convenient online submission

- Thorough peer review

- Inclusion in PubMed and all major indexing services

- Maximum visibility for your research

Submit your manuscript at www.biomedcentral.com/submit 